\title{
Treatment of medication-related osteonecrosis of the jaw around the dental implant in a patient with multiple myeloma: a case report
}

\author{
Minyeong Youn, Youngjae Yee, Jun-Young Kim \\ Department of Oral and Maxillofacial Surgery, Yonsei University College of Dentistry, Seoul, Korea
}

\begin{abstract}
The management of medication-related osteonecrosis of the jaw (MRONJ) around a dental implant is difficult. Conservative treatment is recommended, but patients do not exhibit improvement. Thus, several adjunctive therapies have been introduced. This paper describes a case of MRONJ around a dental implant in a 68-year-old man. Treatment with teriparatide was contraindicated because of the patient's history of multiple myeloma. Successful results with hyperbaric oxygen therapy and surgical intervention were achieved. Clinicians treating patients with MRONJ should conduct a thorough examination before selecting the modalities of adjuvant therapy, thereby establishing a solid treatment strategy. (JOURNAL OF DENTAL IMPLANT RESEARCH 2020;39(4):43-47)
\end{abstract}

Key Words: Osteonecrosis of the jaw, Dental implant, Multiple myeloma, Bisphosphonate

\section{INTRODUCTION}

Bisphosphonates (BPs) are a class of drugs commonly used for bone disease owing to their osteoclast-inhibition properties. They have been indicated for various diseases, including osteoporosis, metastatic bone cancer, Paget's disease, and osteolytic lesions in multiple myeloma ${ }^{1,2)}$.

However, their use might lead to significant complications. Marx first recognized and described medication-related osteonecrosis of the jaw (MRONJ) decades ago $^{3)}$. In its 2014 position paper, the American Association of Oral \& Maxillofacial surgeons classified MRONJ into five stages according to the clinical features and suggested treatment strategies based on disease stages ${ }^{4}$. There have also been studies investigating the association between MRONJ risk and the serum levels of bone turnover markers such as serum C-telopeptide of collagen type 1 (CTx), procollagen type $1 \mathrm{~N}$-terminal propeptide (P1NP), and osteocalcin ${ }^{5-7}$. For the serum CTx level, Marx classified $<100 \mathrm{pg} / \mathrm{ml}$ as high risk, $100 \mathrm{pg} / \mathrm{ml}$ to 150 $\mathrm{pg} / \mathrm{ml}$ as moderate risk, and $>150 \mathrm{pg} / \mathrm{ml}$ as minimal risk $^{5)}$. However, it remains quite challenging for clinicians, and there is currently no gold standard treatment. In addition to BP administration and surgical intervention, various adjunctive treatments with laser, ozone, growth factors (platelet-rich plasma or recombinant human bone morphogenetic protein-2), pentoxifylline and tocopherol (PENTO), hyperbaric oxygen (HBO), and teriparatide have been suggested ${ }^{8-13)}$.

Teriparatide, a recombinant human parathyroid hormone, simultaneously stimulates osteoblasts and osteoclasts, thus reactivating bone remodeling ${ }^{14)}$. Since Harper and Fung first described a case of a patient with MRONJ who was successfully treated with teriparatide in 2007, there have been several reports on the effectiveness of teriparatide in the treatment of MRONJ ${ }^{12,14-16)}$. However, owing to its ability to promote osteoclastic bone resorption, teriparatide is contraindicated in patients with cancer and known bone metastasis ${ }^{17}$. There have also been reports on the occurrence of adverse effects with the use of ter-

Received October 30, 2020, Revised November 16, 2020, Accepted November 16, 2020.

(C) Journal of Dental Implant Research.

(i) (-) This is an open access article distributed under the terms of the Creative Commons Attribution Non-Commercial License (http://creativecommons.org/licenses/by-nc/4.0) which permits unrestricted non-commercial use, distribution, and reproduction in any medium, provided the original work is properly cited.

Correspondence to: Jun-Young Kim, Department of Oral and Maxillofacial Surgery, Yonsei University College of Dentistry, 50-1 Yonsei-ro, Seodaemun-gu, Seoul 03722, Korea. Tel: +82-2-228-3134, Fax: +82-2-227-7825, E-mail: jyomfs@yuhs.ac 


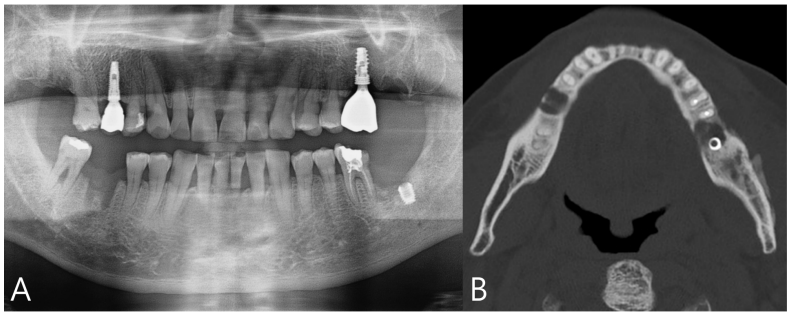

Fig. 1. Initial panoramic radiograph (A) and computed tomography (B) depicting an osteolytic lesion around extraction socket and dental implant.

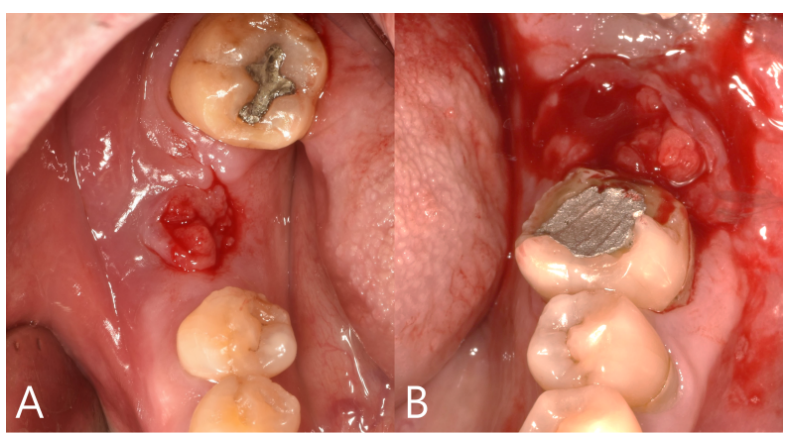

Fig. 2. Intraoral photograph after 6 weeks of conservative care. Soft tissue erythema and swelling are shown (A: right side, B: left side).

iparatide in multiple myeloma, which suggest that the use of teriparatide should be restricted in patients with multiple myeloma ${ }^{18,19)}$.

Herein, we describe the successful treatment of MRONJ around dental implants in a patient with multiple myeloma.

\section{CASE REPORT}

A 68-year-old man was referred to the department of oral and maxillofacial surgery owing to an unhealed wound on the mandible. The patient had previously undergone extraction of the right mandibular molar 6 months prior and curettage around the left mandibular molar implants 9 months prior to his visit. The patient was diagnosed with multiple myeloma and treated with zoledronate (Zometa ${ }^{\circledR}$ ) for the preceding 14 months, after which the treatment was discontinued. Clinical examination revealed gingival redness, swelling, and purulent discharge from both mandibles. Panoramic radiography and computed tomography revealed delayed healing of the extraction socket on the right mandible, diffuse os-

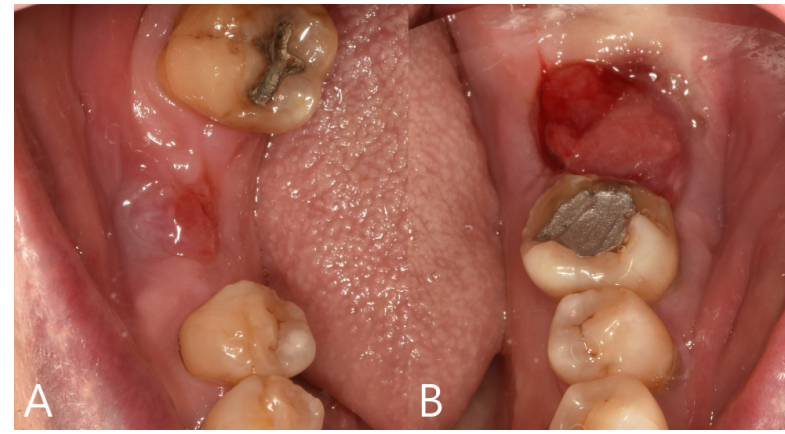

Fig. 3. Intraoral photograph after hyperbaric oxygen treatment showing subsided soft tissue lesion (A: right side, B: left side).

teolysis, and periosteal new bone formation on the left mandible (Fig. 1). As there was no exposed necrotic bone, and the osteolytic lesion was not extended to the inferior border of the mandible, the patient was diagnosed with stage $2 \mathrm{MRONJ}^{4}$. Serum levels of CTx, P1NP, and the parathyroid hormone were examined to evaluate the bone turnover rate. The initial serum levels of CTx and P1NP were $149 \mathrm{pg} / \mathrm{ml}$ and $16.5 \mathrm{ng} / \mathrm{ml}$, respectively. Conservative care with oral antibiotics, pentoxifylline 400 mg twice daily (Trental ${ }^{\circledR}$, HANDOK, Seoul, Korea), tocopherol $200 \mathrm{mg}$ twice daily (Welltamin ${ }^{\circledR}$, Samjin Pharm, Seoul, Korea) (PENTO), and an antibacterial mouth rinse were planned. There was no significant improvement or symptom relief, even after 6 weeks of administration; therefore, adjuvant therapy was planned (Fig. 2). As teriparatide was contraindicated owing to multiple myeloma, treatment with hyperbaric oxygen $(\mathrm{HBO})$ was performed as adjuvant therapy. After HBO therapy, the gingival swelling and redness subsided (Fig. 3). Three months after his first visit, the serum CTx level was 181 $\mathrm{pg} / \mathrm{ml}$ and the osteocalcin level was $8.29 \mathrm{ng} / \mathrm{ml}$. Panoramic radiography and computed tomography revealed the formation of a sequestrum on the bilateral mandible (Fig. 4). Surgical intervention was planned, and sequestrectomy was performed on both sides of the mandible under general anesthesia, and platelet-rich fibrin (PRF) was applied to the surgical defect to promote wound healing. PRF was exposed at the time of stitch-out, but the healing pattern was favorable. HBO therapy was performed postoperatively, and the patient showed good soft tissue healing (Fig. 5), and radiographic examination revealed the progression of bone healing (Fig. 6). 


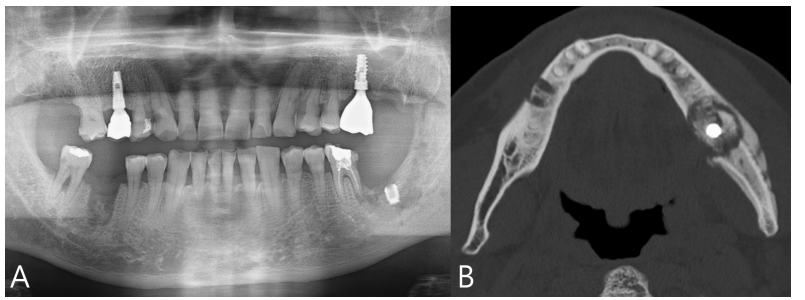

Fig. 4. Panoramic radiograph (A) and computed tomography (B) showing formation of sequestrum around dental implant on left side of mandible and extraction socket on right side of mandible.

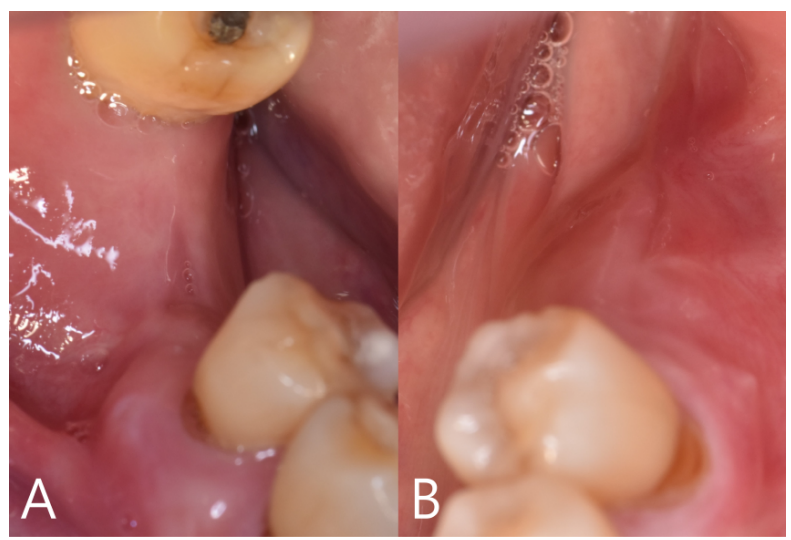

Fig. 5. Intraoral photograph showing excellent soft tissue healing 6 months after surgical intervention (A: right side, B: left side).

\section{DISCUSSION}

As it is known that anti-resorptive and anti-angiogenic agents can induce avascular osteonecrosis of the jaw, this has become a concern for clinicians. The correlation of $\mathrm{MRONJ}$ and the presence or placement of dental implants has been discussed in the literature ${ }^{20-22)}$. Currently, the treatment strategy for MRONJ is determined according to the disease stage based on the 2014 consensus of the American Association of Oral and Maxillofacial Surgeons ${ }^{4)}$. However, patients do not respond to exclusive conservative treatment. Accordingly, various attempts at adjuvant therapy have been made, and among them, teriparatide seems to be promising, as it affects osteoblast function and exerts an anabolic effect. Despite its advantages, the use of teriparatide might be limited. The patient described here was unable to use teriparatide owing to multiple myeloma. In addition to conservative treatment recommended by AAOMS, PENTO and HBO were used as adjuvant therapies. Pentoxifylline improves

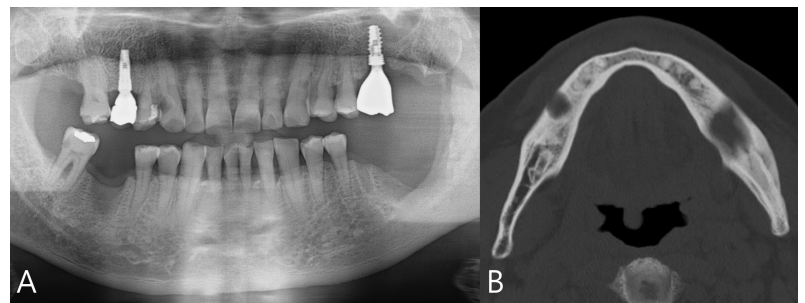

Fig. 6. Radiographic image showing progression of bone healing.

peripheral blood flow by increasing erythrocyte flexibility and vasodilation ${ }^{23}$. It also has an anti-tumor necrosis factor effect, thus inhibiting inflammation and decreasing fibrosis $^{24,25)}$. Tocopherol is a potent oxygen radical scavenger that reduces free radical damage to tissues. The combination of these (PENTO) has been reported to demonstrate an effect on MRONJ ${ }^{11,26,27)}$. Meanwhile, HBO therapy generates reactive oxygen species (ROS) and reactive nitrogen species (RNS) that affect signaling processes critical to wound healing ${ }^{28)}$. ROS and RNS also influence osteoclast differentiation and activity and could possibly counteract a BP-induced suppression of osteoclast activity ${ }^{29,30}$. After the formation of sequestra, surgical intervention with sequestrectomy, including dental implant fixture removal was performed. Excellent treatment results were achieved through a series of procedures.

In conclusion, although teriparatide is a promising treatment modality for MRONJ, a thorough examination should be performed prior to such treatment, and if it is contraindicated, other forms of adjuvant therapy should be considered.

\section{CONFLCT OF INTEREST}

We have no conflicts of interest.

\section{ORCID}

Minyeong Youn, https://orcid.org/0000-0003-2081-8953 Youngjae Yee, https://orcid.org/0000-0002-7954-948x Jun-Young Kim, https://orcid.org/0000-0002-6596-6135

\section{REFERENCES}

1. Patel S, Choyee S, Uyanne J, Nguyen AL, Lee P, Sedghizadeh 
PP, et al. Non-exposed bisphosphonate-related osteonecrosis of the jaw: a critical assessment of current definition, staging, and treatment guidelines. Oral Dis 2012;18:625-32.

2. Ruggiero SL, Drew SJ. Osteonecrosis of the jaws and bisphosphonate therapy. J Dent Res 2007;86:1013-21.

3. Marx RE. Pamidronate(AREDIA) and zoledronate(ZOMETA) induced avascular necrosis of the jaws: a growing epidemic. J Oral Maxillofac Surg 2003;61:1115-8.

4. Ruggiero SL, Dodson TB, Fantasia J, Goodday R, Aghaloo T, Mehrotra B, et al. American association of oral and maxillofacial surgeons position paper on medication-related osteonecrosis of the jaw - 2014 update. J Oral Maxillofac Surg [Internet] 2014;72:1938-56. Available from: http://dx.doi. org/10.1016/j.joms.2014.04.031

5. Marx RE, Cillo JE, Ulloa JJ. Oral Bisphosphonate-induced osteonecrosis: risk factors, prediction of risk using serum CTX testing, prevention, and treatment. J Oral Maxillofac Surg 2007;65:2397-410.

6. Peisker A, Raschke GF, Fahmy MD, Guentsch A, Roshanghias $\mathrm{K}$, König KC, et al. Cross-sectional study of four serological bone turnover markers for the risk assessment of medication-related osteonecrosis of the jaw. J Craniofac Surg 2018;29:e137-40.

7. Soares AL, Simon S, Gebrim LH, Nazário ACP, Lazaretti-Castro M. Prevalence and risk factors of medication-related osteonecrosis of the jaw in osteoporotic and breast cancer patients: a cross-sectional study. Support Care Cancer 2020;28: 2265-71.

8. Fornaini C, Cella L, Oppici A, Parlatore A, Clini F, Fontana M, et al. Laser and platelet-rich plasma to treat medication-related osteonecrosis of the Jaws (MRONJ): a case report. Laser Ther 2017;26:223-7.

9. Agrillo A, Ungari C, Filiaci F, Priore P, lannetti G. Ozone therapy in the treatment of avascular bisphosphonate-related jaw osteonecrosis. J Craniofac Surg 2007;18:1071-5.

10. Freiberger JJ, Padilla-Burgos R, McGraw T, Suliman HB, Kraft $\mathrm{KH}$, Stolp BW, et al. What is the role of hyperbaric oxygen in the management of bisphosphonate-related osteonecrosis of the jaw: A randomized controlled trial of hyperbaric oxygen as an adjunct to surgery and antibiotics. J Oral Maxillofac Surg [Internet] 2012;70:1573-83. Available from: http://dx.doi. org/10.1016/j.joms.2012.04.001

11. Owosho AA, Estilo CL, Huryn JM, Yom SHK. Pentoxifylline and tocopherol in the management of cancer patients with medication-related osteonecrosis of the jaw: an observational retrospective study of initial case series. Oral Surg Oral Med Oral Pathol Oral Radiol [Internet] 2016;122:455-9. Available from: http://dx.doi.org/10.1016/j.000o.2016.06.019

12. Kwon YD, Kim DY. Role of teriparatide in Medication-Related Osteonecrosis of the Jaws (MRONJ). Dent J 2016;4:41.

13. Park JH, Kim JW, Kim SJ. Does the addition of bone morphogenetic protein 2 to platelet-rich fibrin improve healing after treatment for medication-related osteonecrosis of the jaw? J Oral Maxillofac Surg [Internet] 2017;75:1176-84. Available from: http://dx.doi.org/10.1016/j.joms.2016.12.005

14. Kim KM, Park W, Oh SY, Kim HJ, Nam W, Lim SK, et al. Distinctive role of 6-month teriparatide treatment on intractable bisphosphonate-related osteonecrosis of the jaw. Osteoporos Int 2014;25:1625-32.

15. Fliefel R, Tröltzsch M, Kühnisch J, Ehrenfeld M, Otto S. Treatment strategies and outcomes of bisphosphonate-related osteonecrosis of the jaw (BRONJ) with characterization of patients: a systematic review. Int J Oral Maxillofac Surg 2015;44:568-85.

16. Kim JY, Park JH, Jung HD, Jung YS. Treatment of medication-related osteonecrosis of the jaw around the dental implant with a once-weekly teriparatide: a case report and literature review. J Oral Implantol 2019;45:403-7.

17. Tashjian AH, Gagel RF. Teriparatide [human PTH(1-34)]: 2.5 Years of experience on the use and safety of the drug for the treatment of osteoporosis. J Bone Miner Res 2006;21:354-65.

18. Koski AM, Sikiö A, Forslund T. Teriparatide treatment complicated by malignant myeloma. BMJ Case Rep 2010;(January 2006):1-6.

19. Forslund T, Koski AM, Koistinen A, Sikiö A. Malignant myeloma in a patient after treatment for osteoporosis with teriparatide; a rare coincidence. Clin Med Case Reports 2008;1: CCRep.S1026.

20. Guazzo R, Sbricoli L, Ricci S, Bressan E, Piattelli A, laculli F. Medication-related osteonecrosis of the jaw and dental implants failures: a systematic review. J Oral Implantol 2017;43:51-7.

21. Escobedo MF, Cobo JL, Junquera S, Milla J, Olay S, Junquera LM. Medication-related osteonecrosis of the jaw. Implant presence-triggered osteonecrosis: case series and literature review. J Stomatol Oral Maxillofac Surg [Internet] 2020; 121:40-8. Available from: https://doi.org/10.1016/j.jormas. 2019.04.012

22. Kwon TG, Lee CO, Park JW, Choi SY, Rijal G, Shin HI. Osteonecrosis associated with dental implants in patients undergoing bisphosphonate treatment. Clin Oral Implants Res 2014;25:632-40.

23. Delanian S, Porcher R, Rudant J, Lefaix JL. Kinetics of response to long-term treatment combining pentoxifylline and tocopherol in patients with superficial radiation-induced fibrosis. J Clin Oncol 2005;23:8570-9.

24. Delanian S, Lefaix JL. Current management for late normal tissue injury: radiation-induced fibrosis and necrosis. Semin Radiat Oncol 2007;17:99-107.

25. Delanian S, Lefaix JL. The radiation-induced fibroatrophic process: therapeutic perspective via the antioxidant pathway. Radiother Oncol 2004;73:119-31.

26. Magremanne M, Reychler H. Pentoxifylline and tocopherol in the treatment of yearly zoledronic acid-related osteonecrosis of the jaw in a corticosteroid-induced osteoporosis. J Oral Maxillofac Surg 2014;72:334-7.

27. Epstein MS, Wicknick FW, Epstein JB, Berenson JR, Gorsky M. Management of bisphosphonate-associated osteonecrosis: 
Pentoxifylline and tocopherol in addition to antimicrobial therapy. An initial case series. Oral Surgery, Oral Med Oral Pathol Oral Radiol Endodontology [Internet] 2010;110:593-6. Available from: http://dx.doi.org/10.1016/j.tripleo.2010.05. 067

28. Freiberger JJ. Utility of hyperbaric oxygen in treatment of bisphosphonate-related osteonecrosis of the jaws. J Oral Maxillofac Surg [Internet] 2009;67(5 SUPPL.):96-106.
Available from: http://dx.doi.org/10.1016/j.joms.2008.12. 003

29. Lee NK, Choi YG, Baik JY, Han SY, Jeong DW, Bae YS, et al. A crucial role for reactive oxygen species in RANKL-induced osteoclast differentiation. Blood 2005;106:852-9.

30. Ha H, Kwak HB, Lee SW, Jin HM, Kim HM, Kim HH, Lee ZH, et al. Reactive oxygen species mediate RANK signaling in osteoclasts. Exp Cell Res 2004;301:119-27. 